\title{
SMART POWER CONTROL AND MANAGEMENT OF A STANDALONE RENEWABLE ENERGY PRODUCTION SYSTEM
}

\author{
Abdelhaq Amar Bensaber ${ }^{1}$, Mustapha Benghanem ${ }^{1}$ and Mohamed Bourahla ${ }^{1}$ \\ ${ }^{1}$ University of Science and Technology of Oran - Mohamed-Boudiaf- \\ 1abs.abdelhak@gmail.com,mbenghanem6@yahoo.fr, bourah@yahoo.fr
}

\begin{abstract}
The renewable systems are getting attraction because they have been presented as green and reliable power systems for isolated areas, but the high dependency on weather state and the nonlinearity of the system cause a variation in voltage, power and frequency. This article presents a nonlinear controller to attain maximum performance for both sources, then a smart strategy to control the power flow between the hybrid power system and the batteries in order to satisfy the load requirements while keeping the state of charge within secure limits is introduced. To accomplish efficient energy management, we combine two powerful renewable energies: solar and wind, batteries were also used to store the excess of energy or to supply the system with the required energy. The proposed standalone is tested with variable solar irradiation, temperature, and wind speed and the results presented affirm the efficiency of the proposed control.
\end{abstract}

Keywords - PV, MPPT, power flow, management, Wind, Battery, DC/DC converter

\section{INTRODUCTION}

Sustainable and environment friendly energy have been found to be promising solution to deal with issues like pollution and global warming [1,2]. Currently, Wind energy and photovoltaic system are the brightest renewable source of electrical power generation due to its efficiency and reliability [1-5]. Thus, those factors became important topics in industry and research $[6,7]$. First, to attain maximum performance many researchers, control schemes are proposed the vector control with the classical controller, but this controller can provide favourable performance restrictive under ideal voltage conditions. Furthermore, disturbances and parameter variations will leave us with imperfect performance. Therefore, papers have offered many control strategies for DFIG like Sliding Mode Control, smart control or adaptive algorithms, HOSMC [6, 12, 15, 16, 17]. However, climatic conditions affect the power output. Thus, it is difficult to generate the power to fulfil load demand and also the generated power contain frequency/voltage variations [3-5]. The combination of solar and wind energy sources along with a storage unit, such as batteries, offers an excellent solution to problems caused by the stochastic nature of these sources, we have chosen solar and wind energy because they complement each other [6-8]. The subsystems are connected into a DC bus to ensure adaptability of the energy and because this method doesn't require synchronization [9-11]. However, adding battery banks is necessary to satisfy a peak or temporary period load demands $[1$, $12,13]$. Battery is widely used in standalone system because of its high efficiency, quick response, low cost and improve the power-supply stability, quality and reliability.

Received: February 20, 2019

Reviewed: June 21, 2019

Accepted: July 16, 2019 
However, frequent charge and discharge decreases the battery life cycle, thus power management is necessary to prolong the battery life cycle and to suppress the power fluctuation and to supply a quality power to load $[4,13,14]$.

In this paper, control methods are proposed to track the maximum power from the wind/solar energy source to achieve much higher generating capacity factors, then an implementation of a fuzzy logic controller to manage the flow of energy in a wind-PVbattery standalone for island communities. the aim of our method is to optimize the power between the sources for various operation modes, and to preserve the SOC at a reasonable level. The paper is organized as follows. First, we will describe the architecture of the PV and the wind turbine, then the proposed management will be presented. Finally, results will be introduced to verify it performance even under various weather circumstances.

\section{STANDALONE CONFIGURATION}

In this article a PV/Wind/Battery power system with an AC load is considered as presented in Fig 1. The common DC bus is used because it's robust, economics and easy to control [9]. The system is connected to load through a DC-AC inverter associated with an LCL filter. To stabilize the system, a controllable load is considered [1]. The battery system has a bidirectional converter to handle charging or discharging depending on the availability of power. The DC link is connected to the sinusoidal PWM IGBT based inverter which is fed to single phase AC load. The harmonics of the Inverter is filtered by a LC filter. In this study we propose an intelligent management strategy in order to ensure energy of a standalone. To achieve our objective, our strategy is based on two steps is considered. The first step consists on generating the maximum power from the sources in order to generate enough energy to satisfy the load, then an intelligent controller is designed to manage the power flow form the source and play an important role in charging and discharging of the battery.

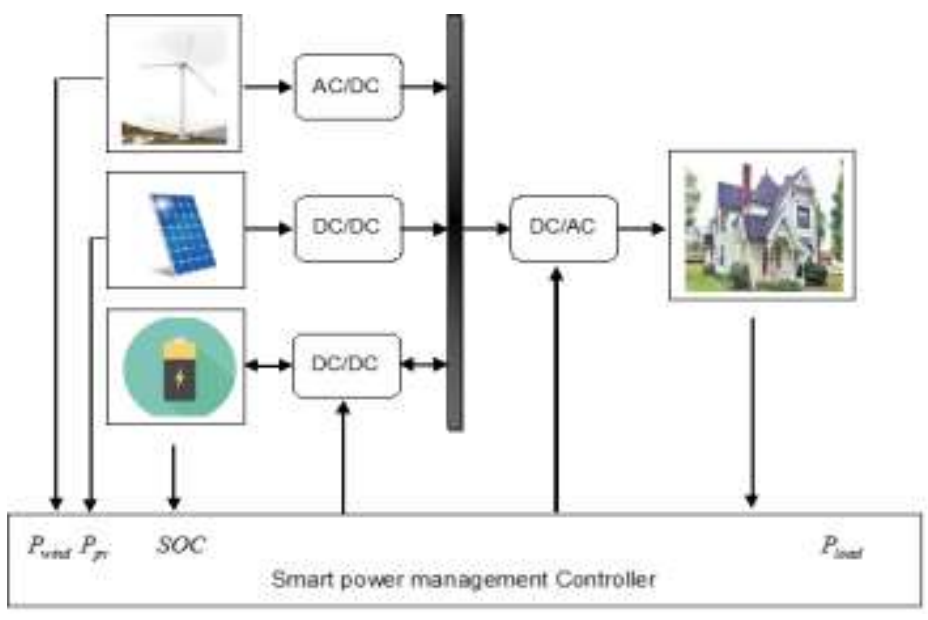

Fig. 1 The Proposed Hybrid system

\section{PV DEVICE}

PV Device will generate electrical power by transforming solar irradiation into direct current [17]. 


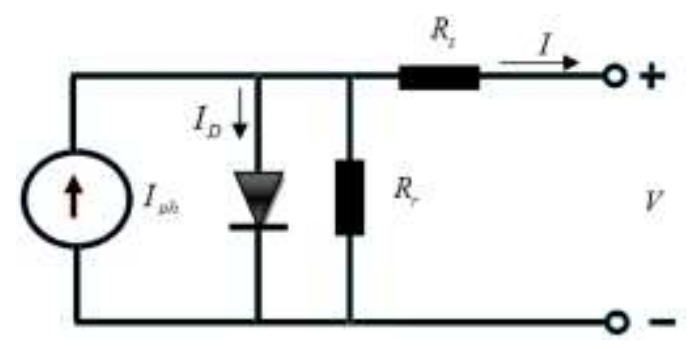

Fig. 2 PV module equivalent circuit

In Fig. 2, the current source presents the incident solar irradiance, we represent the polarization phenomena with a diode, resistance represent the power losses. The mathematical equation is given respectively by:

$$
I=I_{p h}-\underbrace{I_{s a t}\left(e^{\frac{V}{N_{s} A V_{T}}}-1\right)}_{I_{D}}
$$

Where, I: PV current (A); Iph: Photo generated current; V: PV voltage (V); Isat: Diode saturation current.

\subsection{MPPT CONTROL}

In this paper, sliding mode controlled Buck-Boost DC/DC converter powered by Photovoltaic (PV) module for battery charge system is used, the main advantage of this control is its simplicity and robustness in spite of uncertainties in the system and external disturbances and on the other hand it needs relatively less information about the system and also is insensitive to the parametrical changes of the system $[15,16,19,20]$. The sliding mode control has three stages:

Choice of surface

$$
S(x)=\frac{d P_{p v}}{d V_{p v}}=I_{p v}+\frac{d I_{p v}}{d V_{p v}} V_{p v}
$$

Convergence condition

$$
\dot{V}(x)=\dot{S}(x) S(x)<0
$$

Calculation of the control laws

$$
\left\{\begin{array}{l}
u=u_{e q}-k \operatorname{sign}(S)=\frac{I_{p v}}{i_{L}}-k \operatorname{sign}\left(I_{p v}+\frac{d I_{p v}}{d V_{p v}} V_{p v}\right) \\
u_{n}=-k \operatorname{sign}(S)
\end{array}\right.
$$

\section{TURBINE MODEL:}

The power contained in kinetic energy form at a speed $V v$, surface $A l$, is expressed by[18]:

$$
P_{v}=\frac{1}{2} \rho A_{1} V_{v}^{3}
$$

Where $\rho$ is the air density, but WT can regain just a part of that power: 


$$
P_{v}=\frac{1}{2} \rho \pi R^{2} V_{v}^{3} C_{p}
$$

Where: $C_{p}$ is power coefficient [19]. The speed ratio $\lambda$ introduced by:

$$
\lambda=\frac{R \Omega_{t}}{V_{v}}
$$

Where $R$ is the blades length, $\Omega_{t}$ : rotor angular speed. The slow shaft mechanical torque $C t$ is expressed by:

$$
C_{t}=\frac{P_{t}}{\Omega_{t}}=\frac{\pi}{2 \lambda} \rho R^{3} v^{2} C_{p}
$$

\subsection{MAXIMUM POWER TRACKING MPPT}

Direct speed controller (DSC) concept is founded on generating the optimal turbine speed for various wind speed value, and use it as speed reference [20,21]. The reference rotational speed is defined by:

$$
\Omega_{t}^{*}=\left(\lambda_{\text {opt }} v\right) / R
$$

Thus,

$$
\Omega_{m}^{*}=G \Omega_{t}^{*}
$$

We obtain the active power reference by:

$$
P_{s_{-} r e f}=C_{\text {cem_ref }} \Omega_{m}
$$

\section{MATHEMATICAL MODEL OF DFIG}

We have chosen to use the double-fed induction generator because with the help of the bidirectional converter in the rotor it is possible to work in both sub-synchronous and super-synchronous. The electrical model of the machine obtained using Park transformation is given by the following equations [23, 30, 31]:

$$
\begin{array}{ll}
V_{q s}=R_{s} I_{q s}+\frac{d \phi_{q s}}{d t}-\omega_{s} \phi_{d s} & \text { (11) } V_{d s}=R_{s} I_{d s}+\frac{d \phi_{d s}}{d t}-\omega_{s} \phi_{q s} \\
V_{d r}=R_{r} I_{d r}+\frac{d \phi_{d r}}{d t}-\omega \phi_{q r} & \text { (13) } V_{q r}=R_{r} I_{q r}+\frac{d \phi_{q r}}{d t}-\omega \phi_{d r}
\end{array}
$$

\subsection{SECOND ORDER SLIDING MODE CONTROL}

SMC is an interesting nonlinear method approach. Nevertheless, the biggest problem of this control is the chattering phenomenon which causes mischievous effects on the generator because of the discontinuous surveillance and that cause overheating and trigger unmodeled high frequency dynamics [34]. SOMC is an attractive solution [35], it generalizes the sliding mode idea by going to a higher order time derivatives, which decrease chattering and avoid powerful mechanical efforts while maintaining advantages of the SMC [34, 35], such as robustness under uncertainties. Aiming at achieving satisfactory tracking performance for Ps and Qs, the switching functions given next are adopted

$$
\left\{\begin{array}{l}
S_{P}=e_{P}+c_{P} \int e_{P} d t \\
S_{Q}=e_{Q}+c_{Q} \int e_{Q} d t
\end{array}\right.
$$

The integral terms $c p$ sand $c Q$ are positive constant, are added for steady-state errors elimination $[6,34]$. The voltage applied represented in the equation below: 


$$
\left\{\begin{array}{l}
V_{d r}=V_{d r e q}+V_{d r n} \\
V_{q r}=V_{q r e q}+V_{q r n}
\end{array}\right.
$$

The system in reach the sliding surface with the help of the switching control Vdrn and Vqrn; Vqreq and Vdreq are the equivalent control terms ,they make the system move along the sliding manifold and accelerate the response of the system while reducing the steady-state errors[36]. The equivalent controls terms are derived by letting $\dot{S}_{P}=\dot{S}_{Q}=0$, the voltage to be applied to the rotor are expressed as:

$$
\left\{\begin{array}{l}
V_{\text {qreq }}=-\frac{L_{s} L_{r} \sigma}{M V_{s}}\left(P_{s_{-} r e f}^{\cdot}+c_{P}\left(P_{s_{-} r e f}-P_{s}\right)\right)+R_{r} I_{q r}-g w_{s} L_{r} \sigma I_{d r}-g \frac{M V_{s}}{L_{s}} \\
V_{\text {dreq }}=-\frac{L_{s} L_{r} \sigma}{M V_{s}}\left(\dot{Q}_{s_{-} r e f}+c_{P}\left(Q_{s_{-} r e f}-Q_{s}\right)\right)+R_{r} I_{d r}-g w_{s} L_{r} \sigma I_{q r}
\end{array}\right.
$$

Thus;

$$
\begin{cases}V_{d r n}=y_{1}+B_{1}\left|e_{P}\right|^{\frac{1}{2}} \operatorname{sign}\left(e_{Q}\right) & \dot{y}_{1}=B_{2} \operatorname{sign}\left(e_{Q}\right) \\ V_{q r n}=y_{2}-B_{3}\left|e_{P}\right|^{\frac{1}{2}} \operatorname{sign}\left(e_{P}\right) & \dot{y}_{2}=-B_{4} \operatorname{sign}\left(e_{P}\right)\end{cases}
$$

Where $B 1, B 2, B 3$ and $B 4$ are constants

\section{BATTERY CHARGING}

The intermittent nature of renewable sources is the reason why storage systems are important in the hybrid renewable system. Batteries store the surplus power generated and uses it to supply the load if it is required $[1,9,12,14]$. Bidirectional converter is needed to charge or discharge the battery in case of overflowing or deficit of the power [7, 11, 22].The proposed controller for battery charge/discharge control is implemented using FLC. The FLC receives the inputs to the controller and generates a degree of membership relative to each fuzzy set in the membership function then evaluates these fuzzy set memberships and decides which rules should be fired, finally it converts these values into an output control signal. Our controller has two inputs "dP -the sum of wind and PV powers combined-, SOC" and one output-battery reference power Depending on the input values controller generates a desired value for reference battery power. The battery reference power is then divided by the battery voltage to generate the reference current for the battery. The membership functions which used for inputs data are shown in "Figs.3-5" and the rules to be evaluated are given in "Table I".

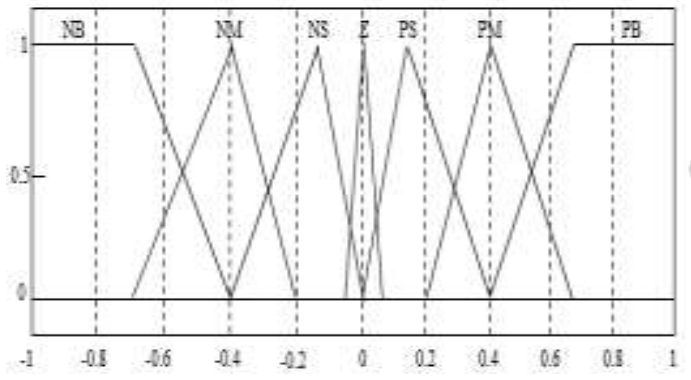

Fig. 3 Input dp

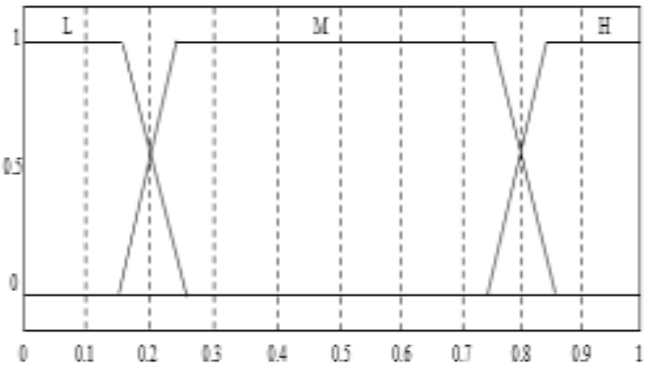

Fig. 4 Input SOC 


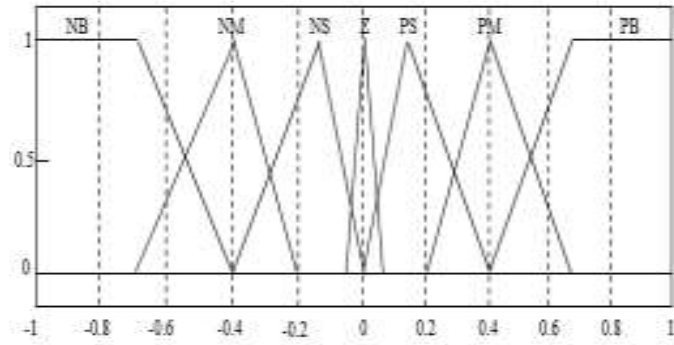

Fig. 5 Output dD.

\begin{tabular}{|c|c|c|c|c|c|c|c|}
\hline$b d^{d P}$ & PB & PM & PS & $Z$ & NS & NM & NM \\
\hline$L$ & NB & NM & NS & $Z$ & $Z$ & $Z$ & $Z$ \\
\hline$M$ & NB & NM & NS & $Z$ & PS & PM & PB \\
\hline$H$ & $Z$ & $Z$ & $Z$ & $Z$ & PS & PM & PB \\
\hline
\end{tabular}

Table I. Fuzzy logic rules

\section{SIMULATION STUDY}

The proposed standalone PV-wind hybrid system with energy storage is tested under different operating conditions and variable load condition as presented in Figure 9 and 10. SOC is considered $60 \%$.

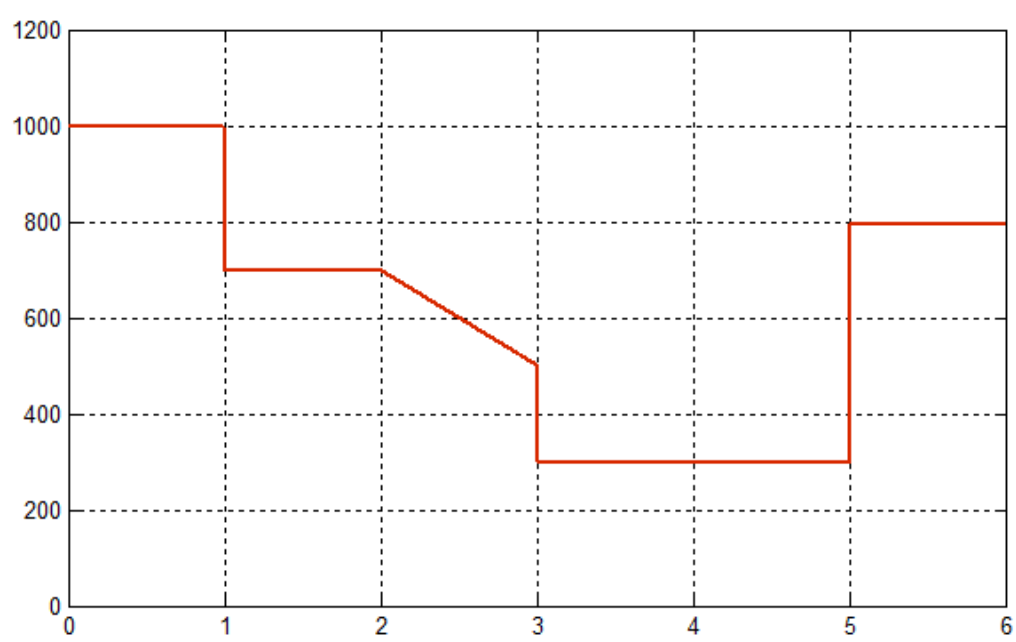

Fig. 6 Irradiation Profile

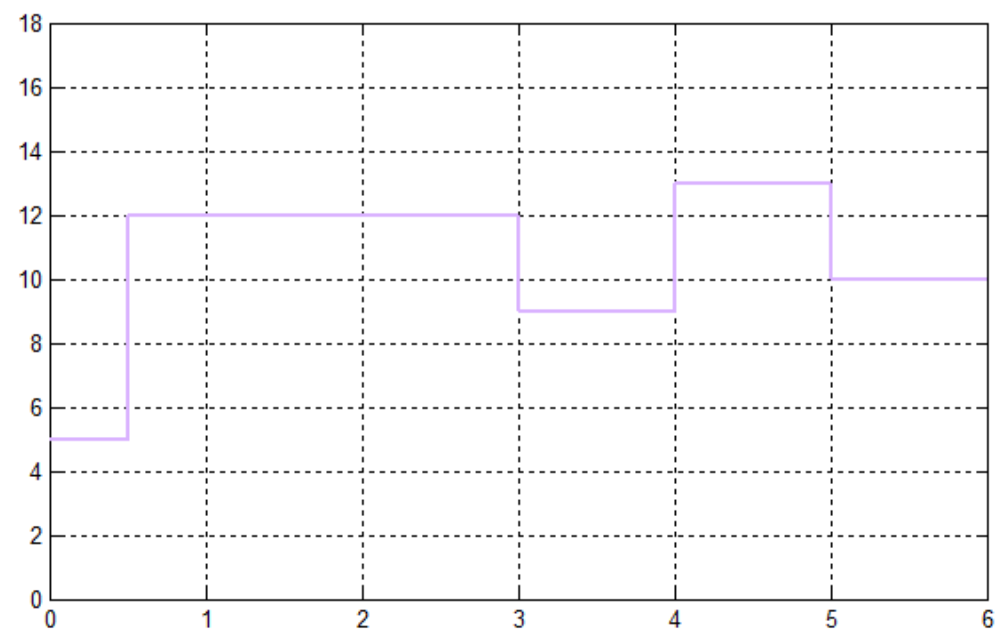

Fig. 7 Wind Profile 


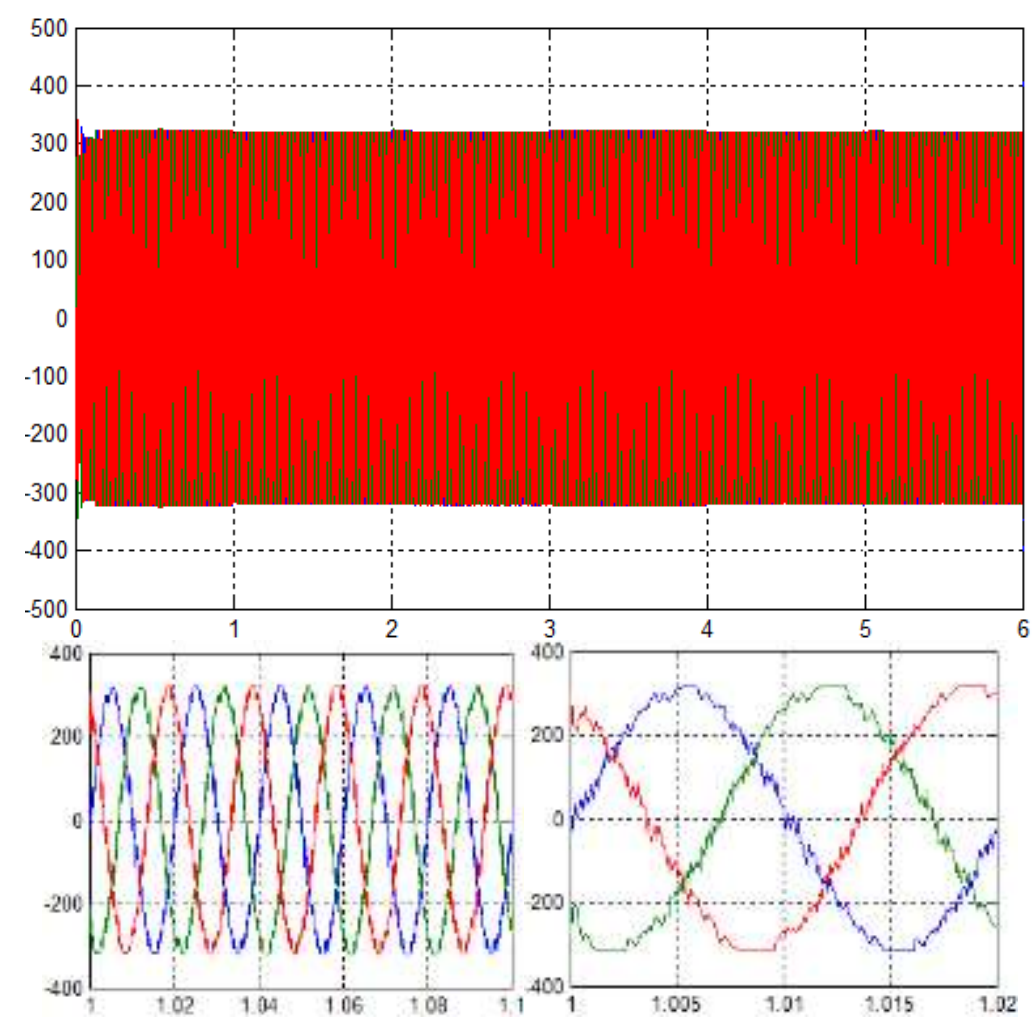

Fig. 8 Output load Voltage

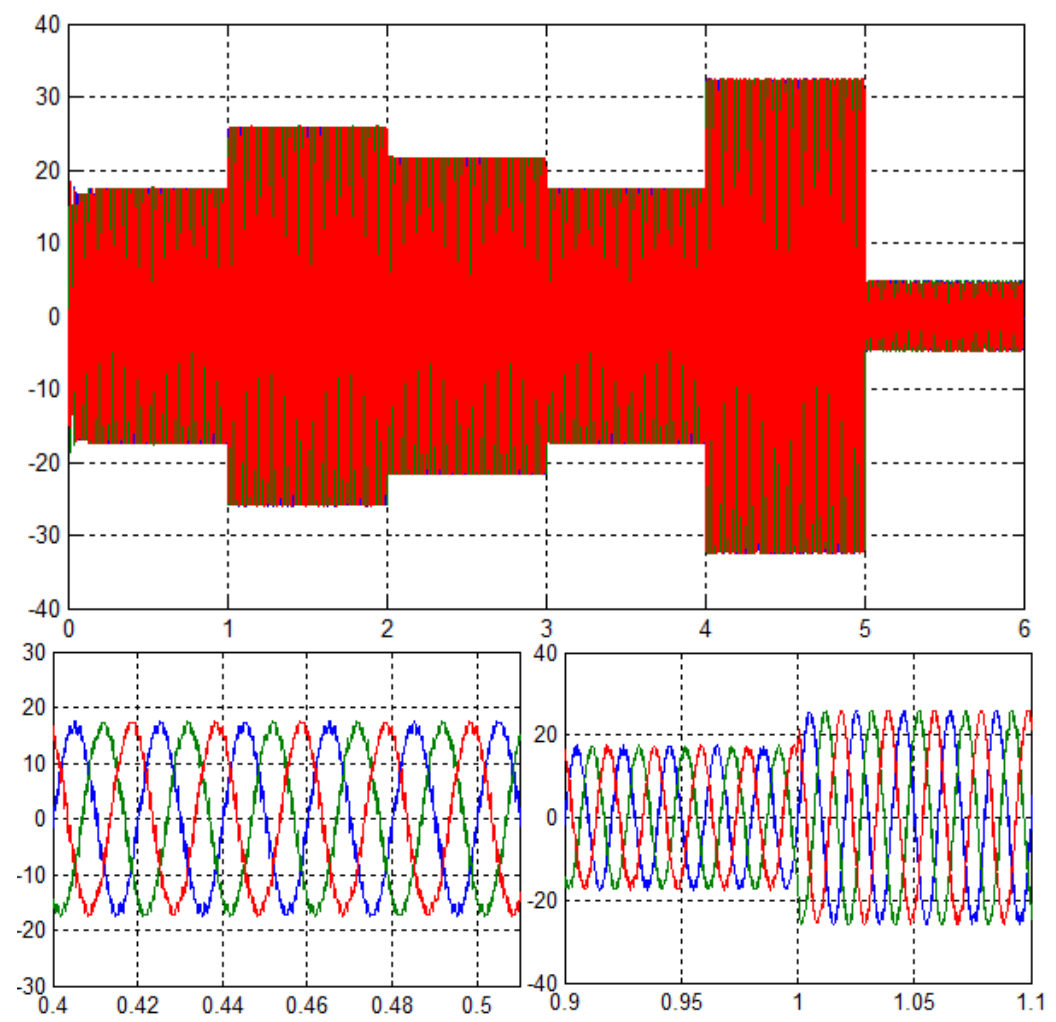

Fig. 9 Output load current 


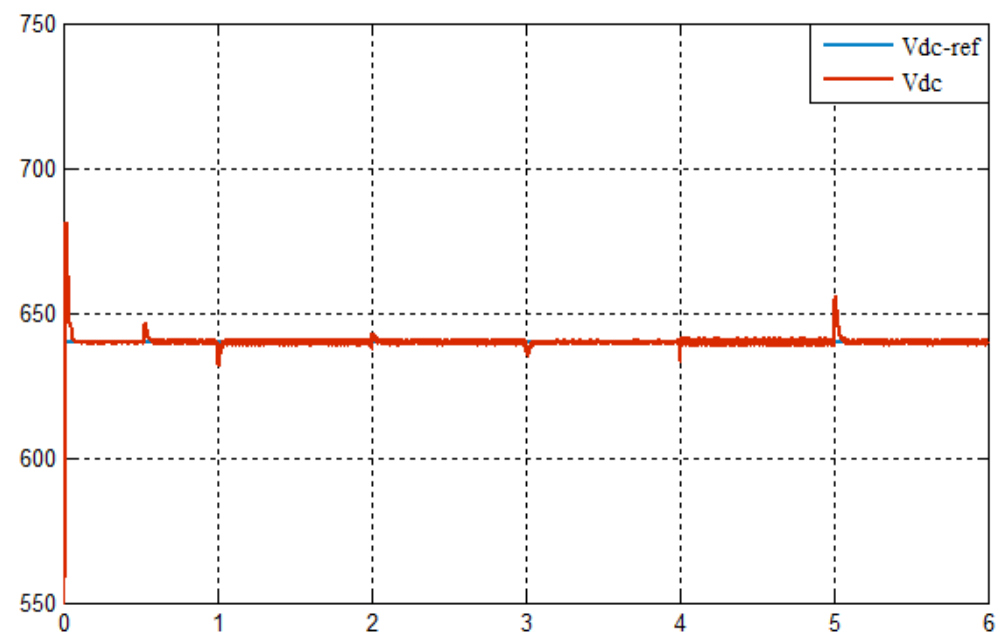

Fig. 10 Dc-link voltage.

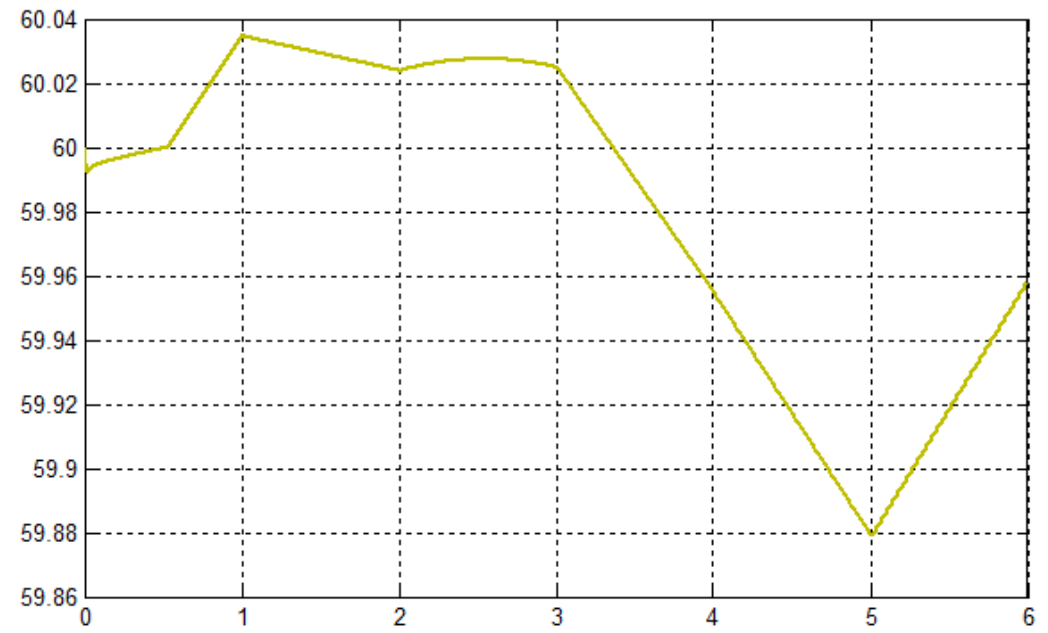

Fig. 11 SOC

The output voltage and load current response are shown in Figures 8 and 9, we can see clearly that load current increase and decrease when the load power change. Further, dclink voltage is constant at $640 \mathrm{~V}$ with a good precision and stability even with a change in hybrid power, load demand and under various weather circumstances, as presented in Figure 10. When the generated hybrid power (PV/wind) is more than the required load power, the additional power will be transfer to the battery, but if the hybrid system power can't meet the load power, the battery bank discharge and fulfil the load with the help of the DC-DC bidirectional converter. We can see that battery power vary (discharge/charge) to maintain the stability of the system as shown in figure 11. It is also can be seen that our system executes satisfactorily under various conditions while having a constant voltage and frequency. 


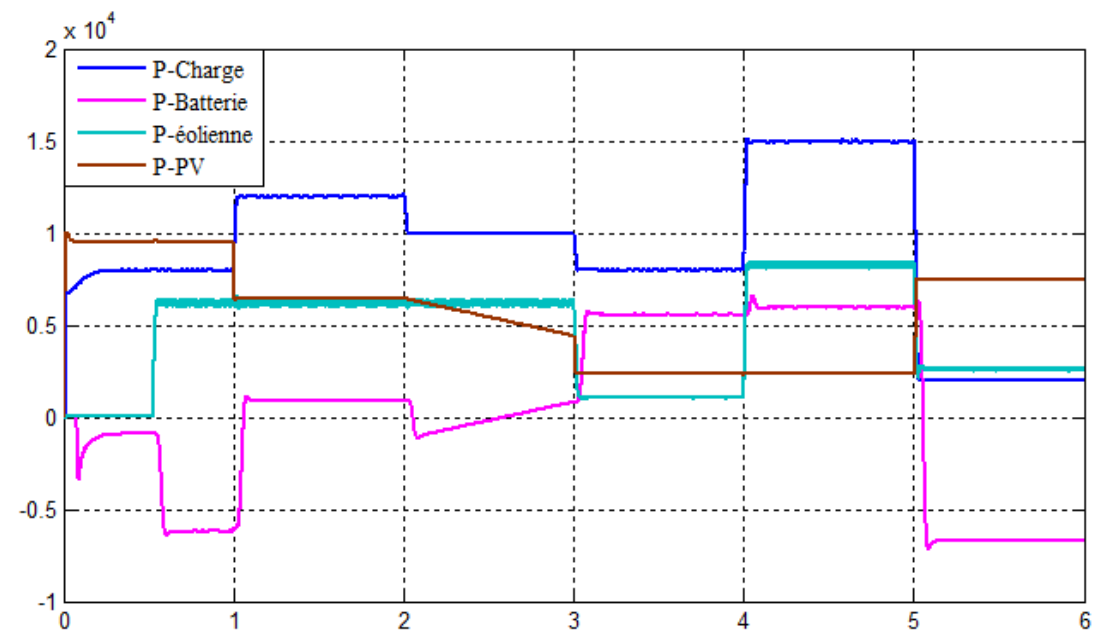

Figure 12: Wind-PV-Battery-Load Hybrid Power

Figure 12 shows the power distribution curve of all generated power sources, it can be observed that, the outputs manage to extract the maximum power even with parameter uncertainties. Load power profile is variable to ensure that the hybrid energy system can serve the load in any case, it is initially $8 \mathrm{~kW}$ and it change to $12 \mathrm{~kW}$ at time $\mathrm{t}=1 \mathrm{sec}$. From time $\mathrm{t}=0$ to time $\mathrm{t}=1 \mathrm{sec}$ the total power generation from wind and solar is more than the load power requirement and the battery is charged during this period. In $t=2.5$ sec total power generation is equal to power demand that is battery power is 0 . From time $\mathrm{t}=4 \mathrm{sec}$ to $\mathrm{t}=5 \mathrm{sec}$ the load increased to and reached $15 \mathrm{kw}$, total power generation is less than power demand. The battery is discharged during this period to meet the load power.

\section{CONCLUSION}

This paper presented a standalone hybrid system to satisfy the electrical load demand for an isolated house. First, a sliding mode controller is used to track the optimum power quickly despite the weather conditions for both sources, then a fuzzy logic controller is implemented to control the power flow even under different scenarios of power generation and power consumption by load while maintaining the battery SOC with in it limits to increases it life. Results showed that the fuzzy controller presented an efficient way to control the flow of energy between input sources and storage units while ensuring a continuous power supply for the load demand even under different operation cases.

\section{REFERENCES}

[1] Bilal, B.O., et al., Study of the influence of load profile variation on the optimal sizing of a standalone hybrid PV/Wind/Battery/Diesel system. Energy Procedia, 2013. 36: p. 1265-1275.

[2] Rahbar, K., J. Xu, and R. Zhang, Real-time energy storage management for renewable integration in microgrid: An off-line optimization approach. IEEE Transactions on Smart Grid, 2015. 6(1): p. 124134.

[3] Bacha, S., et al., Photovoltaics in microgrids: An overview of grid integration and energy management aspects. IEEE Industrial Electronics Magazine, 2015. 9(1): p. 33-46.

[4] Dahmane, M., et al. Renewable energy management algorithm for stand-alone system. in Renewable Energy Research and Applications (ICRERA), 2013 International Conference on. 2013. IEEE.

[5] Jiang, Q., M. Xue, and G. Geng, Energy management of microgrid in grid-connected and stand-alone modes. IEEE transactions on power systems, 2013. 28(3): p. 3380-3389.

[6] Abdelkafi, A. and L. Krichen, Energy management optimization of a hybrid power production unit based renewable energies. International Journal of Electrical Power \& Energy Systems, 2014. 62: p. 19.

[7] Murali, S. and K. Jamuna, Design and Implementation of a converter for Hybrid Energy systems.

[8] Qi W, Liu J, Chen X, Christofides PD. Supervisory predictive control of standalone wind/solar energy generation systems. IEEE transactions on control systems technology. 2011 Jan;19(1):199-207. 
[9] Saad NH, El-Sattar AA, Mansour AE. A novel control strategy for grid connected hybrid renewable energy systems using improved particle swarm optimization. Ain Shams Engineering Journal. 2018 Dec $1 ; 9(4): 2195-214$.

[10] Liu, X., et al., A direct power conversion topology for grid integration of hybrid AC/DC energy resources. IEEE transactions on industrial electronics, 2013. 60(12): p. 5696-5707.

[11] Shagar, B.M., S. Vinod, and S. Lakshmi. Design of DC-DC converter for hybrid wind solar energy system. in Computing, Electronics and Electrical Technologies (ICCEET), 2012 International Conference on. 2012. IEEE.

[12] Bigdeli, N., Optimal management of hybrid PV/fuel cell/battery power system: A comparison of optimal hybrid approaches. Renewable and Sustainable Energy Reviews, 2015. 42: p. 377-393.

[13] Bortolini, M., M. Gamberi, and A. Graziani, Technical and economic design of photovoltaic and battery energy storage system. Energy Conversion and Management, 2014. 86: p. 81-92.

[14] Saib, S. and A. Gherbi. Simulation and control of hybrid renewable energy system connected to the grid. in Energy (IYCE), 2015 5th International Youth Conference on. 2015. IEEE.

[15] Tazvinga, H., B. Zhu, and X. Xia, Energy dispatch strategy for a photovoltaic-wind-diesel-battery hybrid power system. Solar Energy, 2014. 108: p. 412-420.

[16] Wang, T., X. He, and T. Deng, Neural networks for power management optimal strategy in hybrid microgrid. Neural Computing and Applications, 2017.

[17] Kharb, R.K., et al., Modeling of solar PV module and maximum power point tracking using ANFIS. Renewable and Sustainable Energy Reviews, 2014. 33: p. 602-612.

[18] E. Bounadja, A. Djahbar, R. Taleb, Z. Boudjema, A new adjustable gains for second order sliding mode control of saturated DFIG-based wind turbine, AIP Conference Proceedings 1814(1) (2017) 020009.

[19] Abad, G., et al., Direct Control of the Doubly Fed Induction Machine, in Doubly Fed Induction Machine. 2011, John Wiley \& Sons, Inc. p. 363-477.

[20] A.M. Kassem, K.M. Hasaneen, A.M. Yousef, Dynamic modeling and robust power control of DFIG driven by wind turbine at infinite grid, International Journal of Electrical Power \& Energy Systems 44(1) (2013) 375-382.

[21] S. Abdeddaim, A. Betka, Optimal tracking and robust power control of the DFIG wind turbine, International Journal of Electrical Power \& Energy Systems 49 (2013) 234-242.

[22] N.H. Saad, A.A. Sattar, A.E.-A.M. Mansour, Low voltage ride through of doubly-fed induction generator connected to the grid using sliding mode control strategy, Renewable Energy 80 (2015) 583594. 